\title{
The Effects of Trans- Polyoctylene Rubber (TOR) as a Compatibilizer on The Properties of Epoxidized Natural Rubber/Recycled Silicone Catheter (ENR-25/rSC) Vulcanizate
}

\author{
Omar S. Dahham ${ }^{1}$, N.Z. Noriman. ${ }^{1, *}$, S.T. Sam. ${ }^{2}$, H. Rosniza ${ }^{1}$, N. Al-Samarrai Marwa ${ }^{1}, Z$. \\ Shayfull $^{3,4}$, and A. M. Alakrach ${ }^{1}$ \\ ${ }^{1}$ Center of Excellence Geopolymer and Green Technology (CEGeoGTech), Faculty of Engineering \\ Technology (FETech), Universiti Malaysia Perlis (UniMAP), Level 1 Block S2, UniCITI Alam \\ Campus, Sungai Chucuh, Padang Besar, 02100, Perlis, Malaysia. \\ ${ }^{2}$ School of Bioprocess Engineering, Universiti Malaysia Perlis (UniMAP), Kompleks Pengajian \\ Jejawi 3, 02600 Arau, Perlis, Malaysia. \\ ${ }^{3}$ School of Manufacturing Engineering, Universiti Malaysia Perlis (UniMAP), Kampus Pauh, 01000 \\ kangar, Perlis, Malaysia. \\ ${ }^{4}$ Green Design and Manufacturing Research Group, Center of Excellence Geopolymer and Green \\ Technology (CEGeo Tech), School of Materials Engineering, Universiti Malaysia Perlis (UniMAP), \\ Perlis, Malaysia
}

\begin{abstract}
In this study, the influence of Trans- Polyoctylene Rubber (TOR) as a compatibilizer on the cure characteristics, tensile and physical properties of ENR-25/rSC vulcanizate were determined. Five different loading of TOR $(2,4,6,8$ and $10 \mathrm{phr})$ were prepared and added into the vulcanizate. Results indicated that the scorch time $\left(t_{2}\right)$ and cure time $\left(t_{90}\right)$ bacame shorter as TOR increased, while minimum torque $\left(\mathrm{M}_{\mathrm{L}}\right)$ and maximum torque $\left(\mathrm{M}_{\mathrm{H}}\right)$ increased. The incorporation of TOR with the vulcanizates enhanced the tensile strength (Ts), modulus (M100) crosslinking density and hardness values. However, the elongation at break percentage of compatibilized vulcanizates became lower than uncompatibilized vulcanizates.
\end{abstract}

\section{Introduction}

In general, the blending of two or more kinds of polymers could be a beneficial method for the preparation and improvement of materials with properties superior to those of individual constituents [1]. The main purpose of polymer blending is to modify the processing characteristics and also to improve the physical and mechanical properties. In addition, polymer blending could minimize the cost of the final product. Nonetheless, most of polymer blends have poor adhesion between polymer matrix and disperse, which in turn

* Corresponding author: niknoriman@unimap.edu.my 
could lead to poor interfacial adhesion between the phases. Therefore, the compatibilization could be the suitable technique to minimize the problems in polymer blending [2].

Compatibilization is described as a process that uses to overcome the high interfacial tension between the elastomeric and thermoplastic phases. The compatibilization process could achieve either by adding a component, called a compatibilizer, or by improving the interaction of the polymeric components chemically or mechanically. This process could present a smooth transfer of stress between different phases and allow the product to resist the failure under multiple stresses [3]. Compatibilizers are macromolecular species that used for interfacial improvement between different polymer blends.

Trans- polyoctylene rubber (TOR) was used broadly as a compatibilizer for heterogeneous polymer blends, particularly incompatible rubber blends. TOR has a low molecular weight made from cyclo octane by metathesis polymerization. It has crystallizability, which depend on the cis-trans ratio of the double bond. Therefore, it can present a suitable processability in the rubber processing with a temperature range (100-150 ${ }^{0} \mathrm{C}$ ) and a good collapse resistance below the melting temperature due to recrystallization [4]. Pena Bizi et al. have studied the effects of TOR on the properties of NR/SBR blends. Results showed the addition of TOR in blends has improved the hardness, decrease in tear resistance and no effect on the resilience [5]. Our previous work investigated the influence of TOR on the Properties of Acrylonitrile Butadiene Rubber/Recycled Natural Latex Gloves (NBR/NRL-G) Vulcanizates. The results indicated that the presence of TOR had improved curing characteristics, tensile, physical and morphological properties of the rubber vulcanizate [6].

Here in, we studied the effect of similar compatibilizer (TOR), on the cure characteristic, tensile and physical properties of epoxidized natural rubber/recycled silicone catheter (ENR-25/rSC) vulcanizate.

\section{Experimental}

\subsection{Materials, Preparation and Testing}

Table 1 shows the materials that used in this work. Epoxidized natural rubber with 25 epoxidation (ENR-25) was provided from Malaysian Testing Laboratory Sdn. Bhd. While Sulphur, N-cyclohexyl-2-benzothiazole sulphonamide (CBS), Stearic acid, zinc oxide $(\mathrm{ZnO})$ and trans polyoctylene rubber (TOR) were supplied from Anchor Chemical Co. (M) Ltd. Recycled Silicone Catheter (rSC) was supplied from Teleflex Sdn. Bhd. as rejected Silicone Catheters from the factory.

Two-roll mill machine X (S) K - 160 X 320 was used for rSC mastication and then Grinding process was conducted using Grinder RT 34 to form rSC with (1-2mm) particle size. The mixing of rSC with ENR-25 and chemicals was accompanied using same two-roll mill according to ASTM D 3184-89. Monsanto Moving Die Rheometer (MDR 2000) was utilized for Cure characteristics based on ASTM D 2240-93 at $160{ }^{\circ} \mathrm{C}$. Electrically hot press machine was utilized for rubber vulcanizate molding based on respective cure time at 160 ${ }^{0} \mathrm{C}$ and under 30 tonne pressure. Dumbbell-shaped mold was utilized to form tensile test species and then universal testing machine (Instron 5582) was used according to ASTM D412. Shore-A Durometer (Asker, Kobunshi Keiki Co. Ltd) was used for hardness test. Toluene solvent was used for swelling test according to ASTM D3616 and Flory-Rehner equation was used for crosslink density calculations using swelling test data [7]. 
Table 1. The formulation of ENR-25/rSC/TOR vulcanizates.

\begin{tabular}{|c|c|c|c|c|c|c|}
\hline \multirow{2}{*}{ Ingredients } & \multicolumn{7}{|c|}{ phr } \\
\cline { 2 - 7 } & R0 & R10 & R20 & R30 & R40 & R50 \\
\hline ENR-25 & 100 & 100 & 100 & 100 & 100 & 100 \\
\hline ZnO & 5 & 5 & 5 & 5 & 5 & 5 \\
\hline Stearic Acid & 2 & 2 & 2 & 2 & 2 & 2 \\
\hline CBS & 1 & 1 & 1 & 1 & 1 & 1 \\
\hline Sulfur & 2 & 2 & 2 & 2 & 2 & 2 \\
\hline rSC & 10 & 10 & 10 & 10 & 10 & 10 \\
\hline TOR & 0 & 2 & 4 & 6 & 8 & 10 \\
\hline
\end{tabular}

\section{Result and discussion}

\subsection{Cure Characteristics}

The cure characteristics (scorch time $t_{2}$, cure time $t_{90}$, minimum torque $\mathrm{M}_{\mathrm{L}}$ and maximum torque $\mathrm{M}_{\mathrm{H}}$ ) of ENR-25/rSC/TOR vulcanizates are listed in Table 2 respectively. It is observed clearly that $t_{2}$ and $t_{90}$ became shorter with increasing TOR content in the vulcanizates. This was because of the characteristic nature of TOR as a compatibilizer. Furthermore, TOR also could act as an unsaturated rubber, which led to increasing of bonding between TOR and elastomer in short time. $\mathrm{M}_{\mathrm{L}}$ shown decreasing as TOR content increased. This could be due to the plasticizer effect of TOR, which in turn led to reduce the viscosity of the vulcanizates. Consequently, the processability of the vulcanizates had improved.

In contrast, $\mathrm{M}_{\mathrm{H}}$ shown an opposite trend, which increased as TOR content increased in the vulcanizates. This was contributed to the unsaturated structure of TOR, which reacted with the elastomer and improved the crosslink density of the vulcanizates [8].

Table 1. The cure characteristics of ENR-25/rSC/TOR vulcanizates.

\begin{tabular}{|c|c|c|c|c|}
\hline TOR & $\mathbf{t}_{\mathbf{2}}$ (min) & $\mathbf{t}_{\mathbf{9 0}}(\mathbf{m i n})$ & $\mathbf{M}_{\mathbf{L}}(\mathbf{d N m})$ & $\mathbf{M}_{\mathbf{H}}(\mathbf{d N m})$ \\
\hline $\mathrm{R} 0$ & 1.12 & 7.1 & 6.9 & 23.9 \\
\hline $\mathrm{R} 2$ & 0.50 & 5.8 & 5.1 & 27.1 \\
\hline $\mathrm{R} 4$ & 0.45 & 5.1 & 4.8 & 28.2 \\
\hline $\mathrm{R} 6$ & 0.40 & 4.2 & 4.4 & 29.0 \\
\hline $\mathrm{R} 8$ & 0.30 & 3.5 & 3.8 & 32.4 \\
\hline $\mathrm{R} 10$ & 0.20 & 2.8 & 3.1 & 35.8 \\
\hline
\end{tabular}

\subsection{Tensile Properties}

The effects of tensile strength (Ts), elongation at break (Eb) and modulus (M100) on the ENR-25/rSC/TOR vulcanizates are shown in Figure 1,2 and 3 respectively. The values of Ts increased linearly as TOR content increased. The increasing of Ts was attributed to the higher rSC dispersion in NR-25 matrix as TOR increased, which enhanced the interfacial adhesion of the rubber vulcaniziate. M100 values shown same Ts tendency.

The higher incorporation between rSC and ENR-25 matrix as TOR increased led to increases on M100 values. Eb exhibited decline with the presence of TOR. The increasing of TOR content hindered the flow and mobility of rubber vulcanizates. Therefor, the vulcanizates flexibility decreased [9]. 


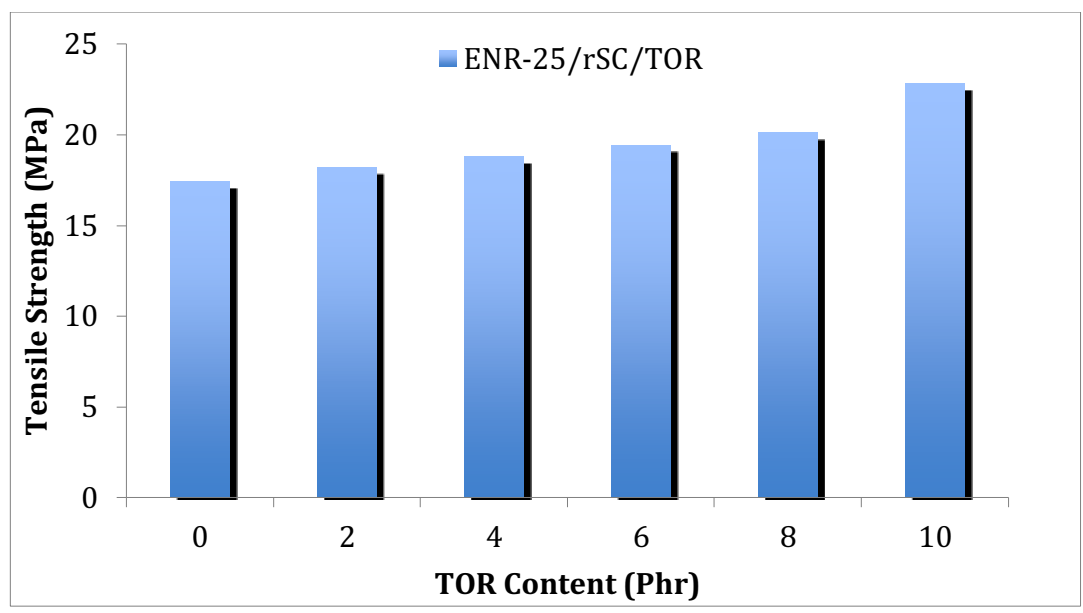

Fig. 1. The variation of Tensile Strength of ENR-25/rSC/TOR vulcanizates.

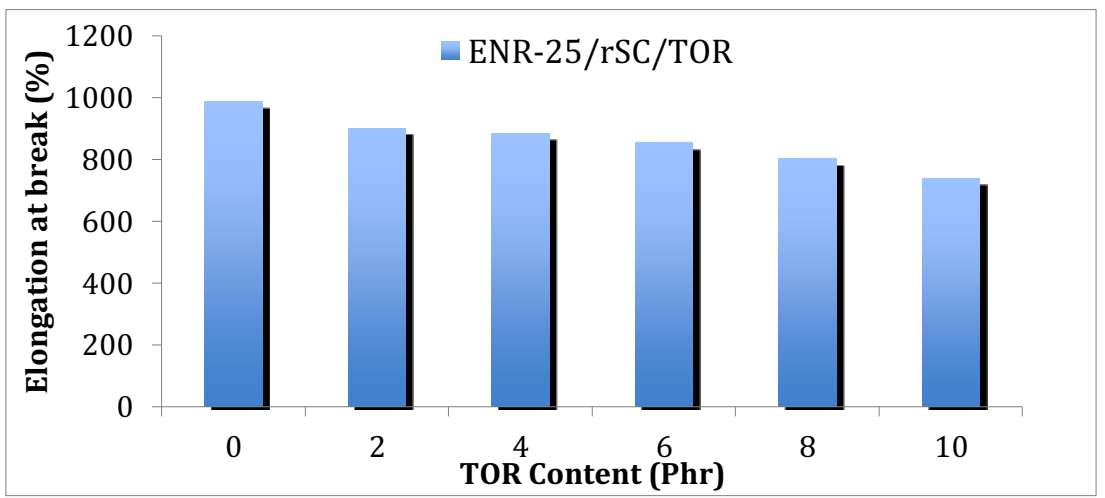

Fig. 2. The variation of Elongation at break of ENR-25/rSC/TOR vulcanizates.

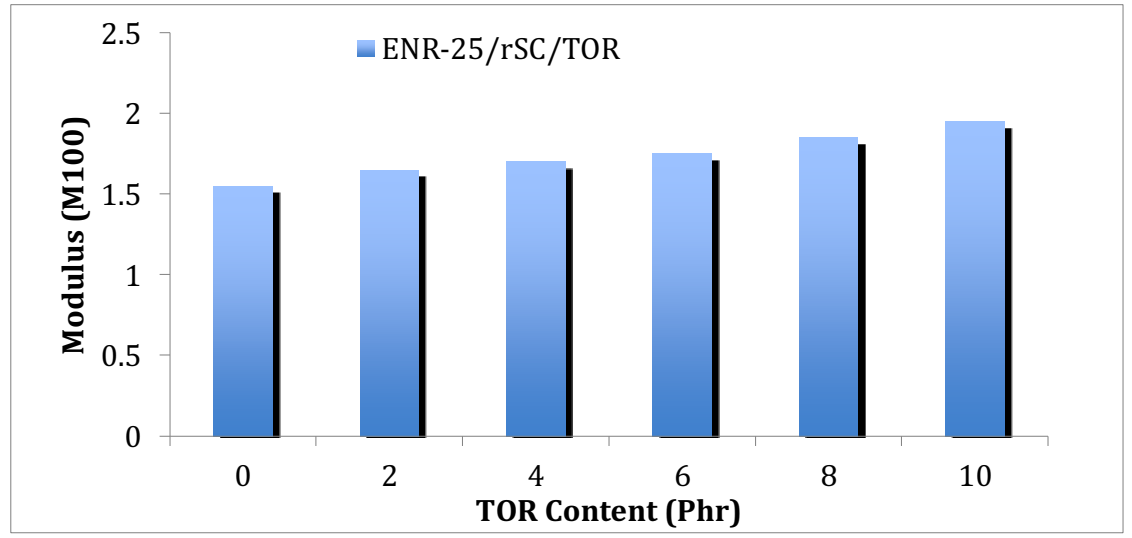

Fig. 3. The variation of Modulus of ENR-25/rSC/TOR vulcanizates. 


\subsection{Physical Properties}

The effects of TOR compatibilizer on the physical properties (crosslink density and hardness) of ENR-25/rSC vulcanizates are displayed in figure 4 and 5 respectively. It's clearly observed that both crosslinking density and hardness values are increased as TOR increased in the vulcanizates. The increasing of crosslinking density led to decreases in Eb, which could be due to the existence of crosslinked precursors, various additives and unreacted curative in the vulcanizates with TOR.

Nah et al. stated that the increasing of hardness values as TOR content increased was might due to the fact that the relative degree of crosslinking was higher than for the other rubber components [10]. Therefore, both crossliniking density and hardness of the vulcanizates are improved.

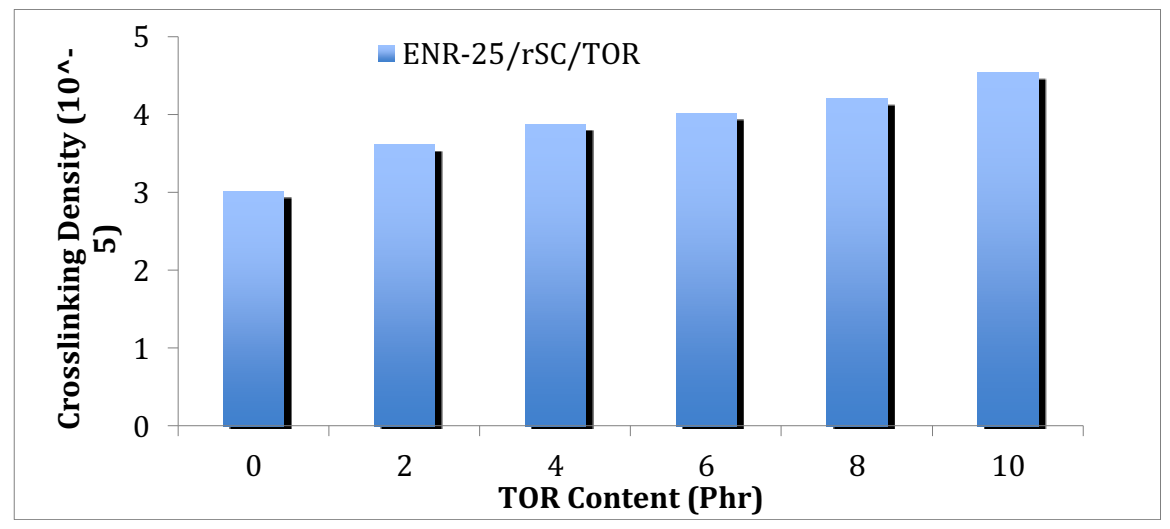

Fig. 4. The variation of crosslinking density of ENR-25/rSC/TOR vulcanizates.

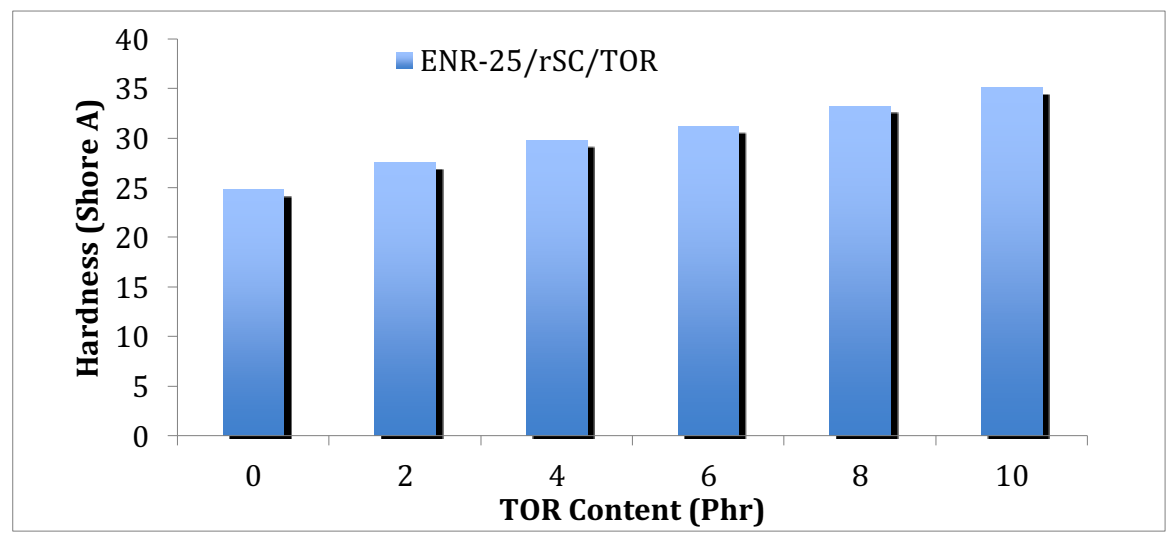

Fig. 5. The variation of hardness of ENR-25/rSC/TOR vulcanizates.

\section{Conclusion}

Generally, the existence of TOR as a compatibilizer made improvement on overall properties of ENR-25/rSC/TOR vulcanizates. The increasing of TOR in the vulcanizates 
has shortened the scorch and cure time and increased the toque. Moreover, The tensile and physical properties of the vulcanizates have increased as TOR content increased.

The authors would like to acknowledge the Fundamental Research Grant Scheme (FRGS) Phase 1/2015 (9003-00523) under Ministry of Higher Education, Malaysia.

\section{References}

11. N.Z. Noriman, H. Ismail, A.A. Rashid, Polym. Test., 29, 200 (2010)

12. Paul, D. R, Polymer Blends, 1, 353 (2012)

13. A. Tedesco, R.V. Barbosa, S.M.B. Nachtigall, R.S. Mauler, Polym. Test., 21, 11 (2002)

14. M. Awang, H. Ismail, M.A. Hazizan, Polym. Test., 26, 779 (2007)

15. C.M.P. Bizi, N.R. Demarquette, J. Appl. Polym. Sci., 109, 445 (2008)

16. O.S. Dahham, N.Z. Noriman, H. Kamarudin, S.T. Sam, M.F. Omar, A.M. Mustafa Al Bakri, H. Rosniza, J. Appl. Polym. Sci., 815, 59 (2015)

17. P.J. Flory, J. Rehner, Journal Chemistry Physics, 11, 512 (1943)

18. N.Z. Noriman, H. Ismail, A.A. Rashid, J. Appl. Polym. Sci., 126(S2), (2012)

19. N. Hayeemasae, I. Surya, H. Ismail, Int. J. Polym. Anal. Charact., 1 (2016)

20. C. Nah, S.C. Han, B.W. Jo, W.D. Kim, Y.W. Chang, J. Appl. Polym. Sci., 86, 125 (2002) 